Send your letters to the editor, British Dental Journal, 64 Wimpole Street, London W1G 8YS Email bdj@bda.org

Priority will be given to letters less than 500 words long. Authors must sign the letter, which may be edited for reasons of space

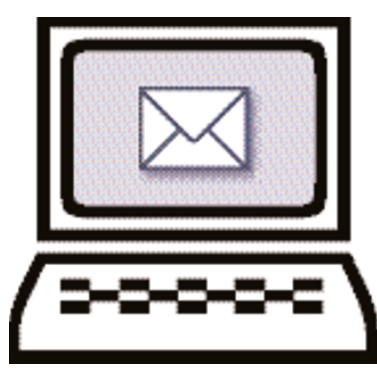

\section{Adult psychiatry}

Sir, this advertisement was featured in the classified section of the $B D J$ on 26 November 2005 (Vol. 199 No. 10): 'Applications for Specialist Registrars in General Adult Psychiatry North Western Deanery (Manchester/ Lancashire). (Ref: SPR57F)'

I wonder if this was a misprint by the $B D J$ or whether they have foreseen that with the arrival of the new contract, some disillusioned dentists may be thinking of moving to psychiatry or may end up psychiatrics, if they don't meet up their UDA targets?

If I apply as a dentist with BDS, FDS, Dip.D. Sed. and Specialist in Surgical Dentistry, would I be short-listed? Or am I psychiatric?

V. Egemonye

London

doi: 10.1038/sj.bdj.4813357

\section{Risky circumstances}

Sir, with statutory registration of DCPs approaching, I believe I have identified a potential problem with the legislation which could leave members of the profession open to legal challenge. I currently employ a student as a dental nurse on Saturday mornings and I approached the GDC to enquire if as a dental student, using the training exemption, he could continue to work part-time as a DSA, following the introduction of registration. I was informed that a dental degree will not be considered a suitable training course to allow someone to practise as a dental nurse. Furthermore, qualified practitioners will only be able to assist a colleague if the duties undertaken are considered to be within their competence and if suitable supervision from a registered nurse is available.

While it should be possible for any dentist assisting a colleague to claim competence, what will happen in the event of a mishap or patient complaint? Any competent lawyer will certainly use this ruling to attack the profession and I therefore believe that in these circumstances we will all be at risk.

It would also appear that, at the present time, no exemption to this rule has been made for dental students practising within a teaching hospital. This means that every time one dental student assists another they will be guilty of illegal practice and again open to legal challenge.

Surely it is possible for the GDC to introduce a hospital exemption for students, or ideally to declare that a dental degree is a suitable qualification for someone to enter the dental nurse register if they should wish to do so? While it is unlikely many of us would wish to register as a dental nurse, this would at least protect both students and practitioners.

P. Martin

Leicester

doi: 10.1038/sj.bdj.4813358

\section{Encourage mentoring}

Sir, the GDC is reviewing the CPD requirements for dentists for recertification. CPD mandatory requirement is now fully in place and works well. Most dentists build up their hours of CPD and often have more than required. Hopefully this system will continue. However if the GDC want to impose certain elements that have to be completed within a year, then dentists will need support. CPR courses are not usually a problem to organise within practice, but radiology courses are not always readily available. IRMA should be achievable every three years. Regarding the notion of practical courses for competence testing for all dentists - very difficult to organise who will do the testing? Dentists are very busy and we have just settled down to the idea of mandatory recertification. Even though peer review and audit cannot directly test a dentist's competence, it can at least be used by their appraisers to review PDP ... which is what most GDPs try and do anyway. Personally I feel the GDC should encourage the idea of 'mentoring' and 'appraisal' as part of a PDP and then let the
GDPs decide to attend 'hands-on courses' to fulfil those areas they feel they need to develop.

\section{Parsons}

Sheffield

doi: 10.1038/sj.bdj.4813359

\section{Pride in your profession}

Sir, having found no obituaries in Vol. 200 No. 1 I turned to my next priority the letters page - and on reading Dumbing down dentistry (BDJ 2006;

200: 2) I had to check at the end to make sure it was not my name as the writer! C. Bosley's experience and opinions match mine in all but minor details.

In my humble but accurate opinion anyone who signs up for the nGDS needs his/her head read; dentists have had a nice little lead-in to private practice and it is time the myth of the NHS, as currently operated and even more so as proposed be nailed for good. Denplan and similar subscription schemes are much closer to Nye Bevan's original idea of a service 'free at the point of use, in exchange for modest contributions' than the current NHS dental scheme. And very much better for the patients, who need dental care, not fee-for-item or UDA based treatment schemes.

There is no longer any moral reason for defending NHS dentistry. We didn't make extravagant promises about everyone having a NHS dentist by 2000AD; that was a politician's promise, ie one made to attract votes but which somebody else is expected to fulfil!

To give up your freewill and control of your business to bureaucrats and politicians would be a gross dereliction of duty to yourselves, your staff and most of all to your patients. You have your freedom and you know what is needed in your practice better than any PCT or whatever they are called. You have the interests of your practice and patients at heart and it's your name over the door; be proud of it and be proud of the service you offer and be proud to 
own a prosperous business that will still be there to serve your community when all the fly-by-night politicians and hangers-on have moved on, to muck up someone else's enterprise.

I remember hearing Ken Adam - of

Admor fame - saying at a meeting 20-odd years ago that dentistry was a good profession to be in before the NHS began and it will still be when the NHS has gone. D. Rowe

Whitstable

doi: $10.1038 /$ sj.bdj.4813360

\section{Specialist opinion}

Sir, I am concerned by the advice given in Scully and Felix's recent update article on oral cancer regarding biopsies of suspected malignancies in general practice (BDJ 2006; 200: 13-17).

I cannot emphasise too strongly that I consider this advice inappropriate and potentially misleading. The over-riding principle is urgent referral of suspicious oral lesions to specialist maxillofacial surgery, oral medicine or head and neck cancer units where all patients with suspected oral cancer should be seen for clinical assessment prior to any interventional or biopsy procedures being carried out. Nonspecialist biopsies delay referral, are often inadequate for diagnostic purpose and may confuse or obscure important clinical features. In some cases, smaller lesions have actually been excised leading to considerable patient assessment difficulties, ultimately compromising patient care. Ideally, the clinician with ultimate management responsibility for the cancer patient should be the one to carry out assessment and biopsy. All head and neck cancer units see patients with suspected malignancy within two weeks (the "two week suspected cancer referral guideline') and the situation as suggested by Scully and Felix whereby 'a specialist opinion is not readily accessible' should not arise in modern clinical practice.

\section{P. J. Thomson}

Northern Head and Neck Cancer Unit Newcastle-upon-Tyne

Professors Scully and Felix respond: We thank Professor Thompson for his interesting comments and opinion. As we have stated, we believe that the GDP should be competent and have confidence to undertake this procedure. In regard to the two week referral guideline this relates to the $U K$ and as the readership of the $\mathrm{BDJ}$ is not restricted to the UK there are undoubtedly areas where ' $a$ specialist opinion is not readily accessible'.

doi: 10.1038/sj.bdj.4813361
Selective dental history

Sir, we have read the series by Gelbier on 125 years of developments in dentistry, 1880-2005. However we would wish to raise an issue with Part 1: British dental and other journals (BDJ 2005; 199: 389395).

As the current and past editor of the Journal of Dentistry, developed from the Dental Practitioner (1950-1972), we were disappointed by the selectivity of Professor Gelbier's reference to 'other nineteenth century journals'. The Journal of Dentistry, first published in 1973, has arguably been one of the leading UKbased dental periodicals in recent times evidenced by its high citation index. Perhaps Professor Gelbier's article was not intended to encompass such notable publications as the Journal of Dentistry but this is unclear as is the enormous contribution UK dental journals have and continue to make to existing dental literature internationally.

\section{A. D. Walmsley \\ N. H. F. Wilson \\ By email \\ doi: $10.1038 /$ sj.bdj.4813362}

\section{Teeth for grenades}

Sir, I congratulate Professor Gelbier on his series of articles on the development of dentistry in the past 125 years.

However, I have to point out an error over the dates of the formation of the Armed Forces Dental Branches. The Royal Naval Dental Service was launched by Admiralty Order in Council on 22 January 1920, a year before the Army Dental Corps was authorised by Royal Warrant on 4 January 1921. The RAF Dental Service was inaugurated on 1 July 1930, although efforts to this end were started in 1925.

Readers might wonder why front teeth were no longer required to fire breachloading guns. In fact, a dental standard was introduced in 1678 for grenadiers requiring them to have sufficient front teeth to bite open the fuses of their grenades and in 1696 a similar one for musketeers to release the gunpowder in their cartridges. The removal of the front teeth of a man of military age became a punishable offence until 1856 when rim-fire and centre-fire cartridges were introduced.

J. V. Holland

Suffolk

doi: $10.1038 /$ sj.bdj.4813363

\section{Sad mythical statements}

Sir, as a retired orthodontist I would take issue with some points in Mr Horobin's letter of 14 January (BDJ 2006; 200: 3).

I would ask, what is his scientific evidence that "It has long been obvious that malocclusion, like asthma and diabetes, is a disease of modern civilisation'? Secondly, 'Soft food and a congested upper airway are, without doubt, the prime aetiological factors in modern day crooked teeth'. Thirdly, 'It is the narrow maxilla that these factors produce, crowds the teeth and holds back the developing mandible'.

These myths were firmly debunked 72 years ago by Professor James Brash in his Dental Board Lectures of the 1920s, and supported by the work of researchers such as Professor C. F. Ballard and R. Rix and others in the 1950s. Their conclusions that malocclusion is basically of genetic origin, and that environmental factors play a very small almost negligible part, were truly scientific investigations and ones that form the basis of modern orthodontics.

It is sad to see Mr Horobin making statements that 'The above seems so self evident' without a shred of scientific evidence to support them.

\section{R. T. Broadway}

Winchester

doi: $10.1038 /$ sj.bdj.4813362

\section{Isolated exceptions}

Sir, Dr Korada's letter, Antibiotic prophylaxis: a myth? (BDJ 2006; 200: 5) highlights one of the most common problems with evidence-based practice - everyone can quote an exception.

It is imperative to appreciate that there will be patients who do not get infective endocarditis in spite of having accepted risk factors and also those who do in spite of having no risk factors.

I think it is harder for us as surgeons to accept evidence-based practice as we learn much of our craft through our own experience; over the years we develop our own ways of doing what works for us and our patients. However we do have to accept that working parties are unlikely to alter their guidelines based on a few isolated exceptions and if we choose to practise outside of the guidelines we have to be prepared to defend ourselves in court; quoting one previous case is unlikely to be a good defence.

L. Cascarini

Beckenham

doi: 10.1038/sj.bdj.4813365

\section{Treating osteonecrosis}

Sir, I read with great interest the letter by D. Regan (BDJ 2005; 199: 754) from both a professional and personal viewpoint. My father was diagnosed with myeloma in 2002 and the author of the letter was a lecturer during my undergraduate years at Sheffield. As a 
result of my father's diagnosis I have become acutely aware of the problem of jaw osteonecrosis following prolonged use of bisphosphonates. As stated by D. Regan this complication has been widely reported in recent years. I have tried to research the most appropriate way of preventing this complication but cannot find any appropriate advice short of stopping the bisphosphonates three months before treatment, which of course in an emergency situation would not be possible. It has been suggested to me that a high dose of antibiotics preand post-treatment may help to prevent the occurrence of osteonecrosis. Are there any evidence-based protocols that $B D J$ readers are aware of, as this is a complication that is best avoided at all costs?

\section{Z. Harrison}

\section{Bolton}

doi: 10.1038/sj.bdj.4813366

\section{Inappropriate views}

Sir, we would like to express our concern with reference to the letter Surgical specialist lists (BDJ 2005; 199: 249). Our concerns are threefold.

Firstly, the author is not a recognised trainer of Specialist Registrars in Oral and Maxillofacial Surgery and was not party to the entire discussion by the Specialist Advisory Committee to which he referred.

Secondly, the statement that Oral and Maxillofacial Specialist Registrars (in the Mersey region) were not involved in dentoalveolar surgery at the unit in question was factually incorrect, as was the assumption that a similar state of affairs exists in other units. The Specialist Registrars in Oral and Maxillofacial surgery have logbook records of their dentoalveolar surgery training validated by interim Record of In-Training Assessments.

Thirdly, we feel that the views expressed are inappropriate in view of these inaccuracies and potentially alarmist to the general public and the dental profession. We, therefore, invite the author to retract these assertions.

M. Batsone, T. K. Blackburn, M. D. Dodd, J. D'Souza, C. Katre, D. Kissun, S. Laverick, S. Parikh, R. Shaw By email

The author of the letter, G. Woods replies: Sir, the intent of my letter was to pose several questions about the appropriateness of the OMFS and CCST for automatic entry onto the GDC specialist Oral Surgery and Surgical Dental lists but to do so without specific criticism of any individual Spr training.
I apologise if this has been misunderstood. The letter acknowledged that Spr exposure to dentoalveolar surgery probably varied throughout the UK but posed the question as to whether the variation of training is, or is likely to be, acceptable for entry/retention onto the GDC surgical specialist lists.

Given that we live in a time of radical health care change which encompasses revalidation, more specialisation within surgical specialties including OMFS and now the new government body the National Clinical Assessment Service, which is able to look into clinical performance, I still believe that my questions are worthy of consideration. Surely the GDC should continually review and consider its specific requirements for entry and retention on its lists for the protection of the public in the light of any changes in health care delivery?

In specific response to the above letter the holder of the post of rotated Spr at Arrowe Park Hospital is not assigned to any of the our eight weekly minor oral surgical lists but does undertake dentoalveolar surgery on any case that may be allotted to them on the Tuesday list or possibly when in out-patient clinics at other times. The question in my own mind is whether the GDC will consider the extent of this type of exposure sufficient for its specialist surgical lists in the future?

doi: $10.1038 /$ sj.bdj.4813367

\section{Alarming increase in dental sepsis}

Sir, I am writing to report an alarming increase in the number of patients presenting to oral and maxillofacial surgery services with dental sepsis requiring admission for incision and drainage under general anaesthesia. Anecdotally the numbers appeared to be increasing, therefore the numbers presenting to Hull Royal Infirmary in 1999 and in 2004 were audited.

The number of patients presenting with dental sepsis on an emergency basis increased from 17 in 1999 to 25 in 2004 (patients from Hull postcode area only). Patients treated under local anaesthesia or with cellulitis were excluded from the audit. While the figures may not seem large, in percentage terms this represents a $47 \%$ increase. The trend continues in the projected figures for 2005, and the severity of infections now seen is considerable. More than 60\% were not registered with a GDP in either 1999 or 2004 , and the vast majority of referrals were from the Accident and Emergency department at Hull Royal Infirmary.

Death from dental sepsis is rare in the United Kingdom. ${ }^{1,2}$ However as this is a possibility, every dental abscess must be considered potentially life threatening. The rise in numbers of patients with acute dental sepsis has increased the workload of Accident and Emergency staff, who are not primarily trained to deal with dental problems. It has also increased unplanned activity in emergency theatre resulting in the cancellation of elective cases at times of low emergency theatre availability. The forced unpredictable availability of operating time has a deleterious effect on future planning of services.

The East Riding of Yorkshire has the fifth poorest ratio of people per NHS dentist in England $(2932: 1)^{3}$ and the poorest ratio of people to NHS dentist in the Northern and Yorkshire regions. ${ }^{4}$

For those patients not registered with a GDP, attempts to seek treatment from an NHS GDP or Dental Access Centre prior to presentation were not recorded in the audit. Thus it cannot be concluded with certainty that lack of availability of NHS General Dental Practitioners is the main contributing factor to the increase in presentation of acute dental sepsis directly to the hospital setting.

The creation of Emergency Dental Access Centres within the former Hull \&t East Riding Health Authority area over the last five years has not resulted in a reduction in presentation of dental sepsis to the hospital setting. It would appear, therefore, that patients are preferentially continuing to attend Accident and Emergency departments with later, more severe presentations of potentially life threatening dental sepsis, which is wholly preventable. This is a trend that should cause concern within Dental Public Health and poses difficulties in planning services within the secondary care setting in the face of strict NHS targets.

L. Carter

D. Starr

Hull

1. Green A W, Flower E A, New N E. Mortality associated with odontogenic infection! Br Dent 2001; 190: 529-530.

2. Currie W J R et al. An unexpected death associated with an acute dentoalveolar abscess report of a case. Br J Oral Maxillofac Surg 1993; 31: 296-298.

3. Moles D R, Frost C, Grundy C. Inequalities in availability of National Health Service general dental practitioners in England and Wales. Br Dent J 2001: 190: 548-553.

4. Landes D P. Inequalities in availability of NHS GDPs. BrDent J 2001; 191: 354-355

doi: $10.1038 /$ sj.bdj.4813368 